\title{
Papers
}

\section{Reasons for considering leaving UK medicine: questionnaire study of junior doctors' comments}

Philip J Moss, Trevor W Lambert, Michael J Goldacre, Penelope Lee

\begin{abstract}
Objectives To study the reasons given by junior doctors trained in the United Kingdom for considering leaving UK medicine. Design Analysis of replies to postal questionnaire surveys. Setting United Kingdom.

Participants 1326 doctors who qualified in 1999.

Main outcome measure Reasons for considering leaving. Results Of 1047 doctors who indicated that they would stay in medicine but not necessarily in the United Kingdom, 65\% (682) gave reasons for leaving that concerned lifestyle, such as a preference for living outside the United Kingdom; 41\% (433) gave reasons concerning working conditions in UK medicine; and $18 \%$ (184) gave positive work related reasons, such as wanting to work in developing countries. Of 279 doctors considering leaving medicine, $75 \%$ (210) cited working conditions, 23\% (63) cited lifestyle reasons, and 9\% (24) cited positive interests in a different career. Of the 169 doctors who said that they would probably or definitely leave the United Kingdom but remain in medicine, 78\% (132) specified lifestyle reasons. Of the 42 who said that they would probably or definitely leave medicine, $67 \%$ (28) cited working conditions. Conclusions The wish to work abroad, but to stay in medicine, was more common than the wish to leave medicine. The preference for a different lifestyle, particularly to live outside the United Kingdom, is not readily amenable to policy changes to the medical working environment. The smaller numbers of doctors who gave work experience as a reason for considering leaving medicine might be influenced to stay by improvements in working lives.
\end{abstract}

\section{Introduction}

An increase in the number of doctors working in the NHS in England is a major policy initiative in the NHS Plan. ${ }^{1}$ The "improving working lives" programme aims to ensure that everything is done to encourage doctors, once recruited, to remain in the NHS. ${ }^{23}$ Although loss of junior doctors from the NHS has been a longstanding concern of policy makers, the loss of young home trained doctors from the UK medical workforce does not seem to have increased during the 1980s and 1990s. ${ }^{4}$ However, in our regular surveys, the proportion of preregistration house officers who have reported their intention to "continue practising medicine in the United Kingdom for the foreseeable future" declined from around $90 \%$ in the 1980s to $75 \%$ in the 1990 s. $^{5}$ In the past, early expressed intentions have been shown to be a reasonable predictor of subsequent career pathways. Whether or not early indications are followed, it is important to understand why some doctors say that they may want to leave. We report a systematic qualitative study, in which we explored the distinction between the factors that would be amenable to policy initiatives to encourage doctors to stay in UK medicine and other factors that are largely beyond the influence of policy.

\section{Methods}

We regularly survey junior doctors' career intentions. In selected years, we send postal questionnaires to the new graduates of all UK medical schools. For the study reported here, we used information from our survey of graduates of 1999 from all UK medical schools towards the end of their first postgraduate year. Our methods are described in detail elsewhere. ${ }^{6}$ Among other questions, respondents were asked, "Apart from temporary visits abroad, do you intend to practise medicine in the United Kingdom for the foreseeable future?" They were given a choice of five answers: yes, definitely; yes, probably; undecided; no, probably not; and no, definitely not. Respondents who did not answer "yes, definitely" were asked if they were considering one of three possible options: considering practising medicine abroad; considering leaving medicine but remaining in the United Kingdom; or considering leaving medicine and the United Kingdom. They were then asked to specify, if they wished, in their own words in a designated text box, their main reason for considering leaving. In the analysis, we grouped the respondents into "doctors who were considering leaving the United Kingdom" (first response, above) and "doctors who were considering leaving medicine" (second or third response) (fig).

We imported the relevant free text replies into the "N6" qualitative data analysis software package (QSR International Pty, Melbourne, Australia). Some doctors gave a single comment, and others provided several. We coded all comments by each individual doctor. We developed the coding scheme as we read and coded each response. We coded the two groups separately (those who might leave the United Kingdom and those who might leave medicine), to ensure that for each group we developed a set of subcategories ("nodes" in the terminology of N6) that fully reflected the variety of comments of the group members. One of us (PJM) did the coding.

We used the summary terms "working conditions" and "lifestyle choices" to reflect the main reasons for leaving given by the doctors. Working conditions refers to all aspects of their day to day work as doctors, such as pay, working hours, and job satisfaction. Lifestyle choices concerns other aspects of doctors' lives unrelated to work, such as domestic, family, and personal considerations; travel aspirations; or the desire to live in a location with a better climate or a higher standard of living. This distinction, as reported by the doctors themselves, was clear in most responses. 


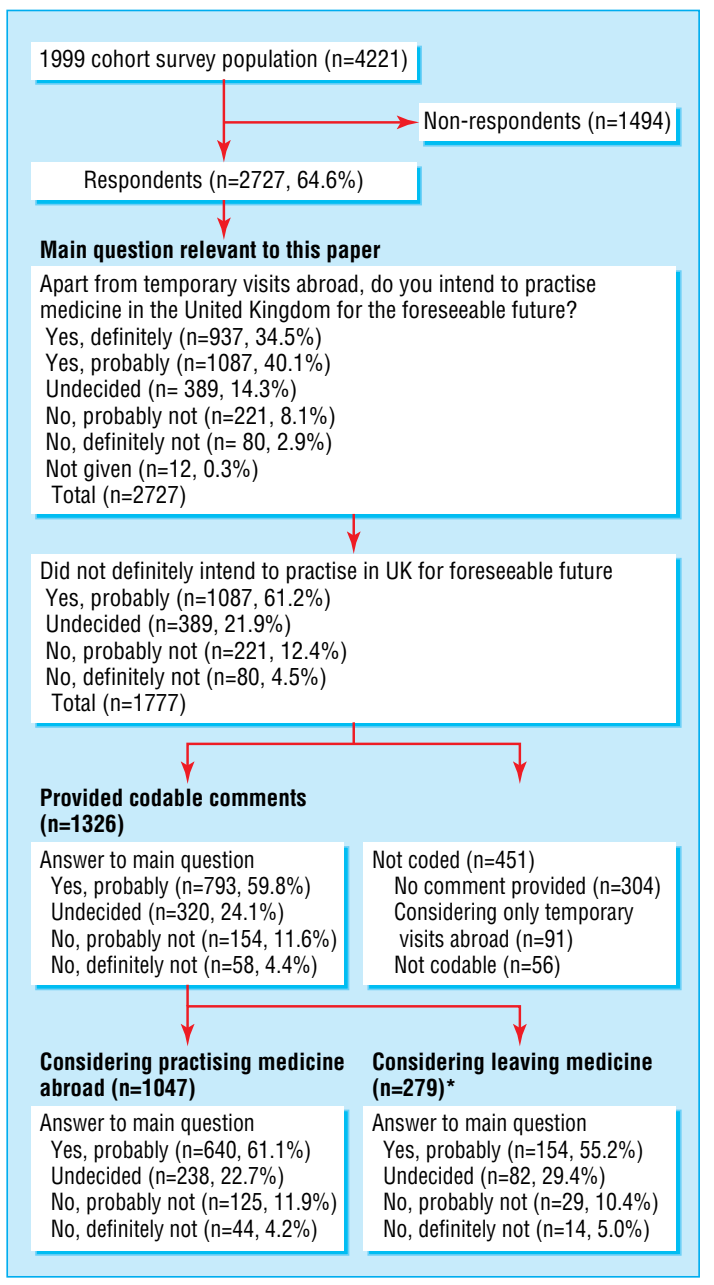

Derivation of data for analysis. * Includes 80 doctors who were considering leaving medicine and leaving the United Kingdom

Some doctors made a connection between the two, particularly in comments about long working hours and their impact on social and domestic life. We defined a third broad category, "work related purpose." For doctors considering leaving the United Kingdom, this refers to those who indicated a positive decision to seek specific work experience by working abroad. For doctors considering leaving medicine, it refers to a positive choice to explore other career options and interests. The subcategory "overseas relief/voluntary work" has been included within the main category "lifestyle choices," because the comments made suggested that the motivation for this choice was related more to lifestyle choice than to working conditions in UK medicine.

We used the search facilities of the N6 software to select responses from those doctors who would probably or definitely not continue practising in the United Kingdom or in medicine. We also extracted the comments of those who commented only on working conditions or only on lifestyle choices, in order to help in assessing the degree to which policy initiatives (which would mainly impact working conditions) could encourage doctors to remain in UK medicine.

\section{Results}

Overall, $2727(64.6 \%)$ of 4221 doctors replied to our questionnaire. Of these, 1777 (65.2\%) did not definitely intend to practise medicine in the United Kingdom (fig). The data for
Table 1 Summary of the main reasons given for considering leaving the United Kingdom or leaving medicine. Values are numbers (percentages*) of respondents who did not definitely intend to practise in the United Kingdom

\begin{tabular}{|c|c|c|c|}
\hline Groups and themes & Women & Men & Total \\
\hline \multicolumn{4}{|c|}{ Considering leaving the United Kingdom } \\
\hline $\begin{array}{l}\text { All not definitely } \\
\text { intending to practise } \\
\text { medicine in the } \\
\text { United Kingdom: }\end{array}$ & $(n=587)$ & $(\mathrm{n}=460)$ & $(n=1047)$ \\
\hline Working conditions & $214(36.5)$ & $219(47.6)$ & $433(41.4)$ \\
\hline Lifestyle choices & $412(70.2)$ & $270(58.7)$ & $682(65.1)$ \\
\hline Work related purpose & $124(21.1)$ & $60(13.0)$ & $184(17.6)$ \\
\hline Other & $5(0.9)$ & $7(1.5)$ & $12(1.1)$ \\
\hline $\begin{array}{l}\text { Probably or definitely } \\
\text { leaving: }\end{array}$ & $(n=100)$ & $(\mathrm{n}=69)$ & $(\mathrm{n}=169)$ \\
\hline Working conditions & $30(30.0)$ & $24(34.8)$ & $54(32.0)$ \\
\hline Lifestyle choices & $80(80.0)$ & $52(75.4)$ & $132(78.1)$ \\
\hline Work related purpose & $12(12.0)$ & $3(4.3)$ & $15(8.9)$ \\
\hline Other & $2(2.0)$ & $7(10.1)$ & $9(5.3)$ \\
\hline \multicolumn{4}{|c|}{ Considering leaving medicine } \\
\hline $\begin{array}{l}\text { All not definitely } \\
\text { intending to practise } \\
\text { medicine in the } \\
\text { United Kingdom: }\end{array}$ & $(n=157)$ & $(\mathrm{n}=121)$ & $(\mathrm{n}=279)$ \\
\hline Working conditions & $114(72.6)$ & $96(79.3)$ & $210(75.3)$ \\
\hline Lifestyle choices & $47(29.9)$ & $16(13.2)$ & $63(22.6)$ \\
\hline Work related purpose & $16(10.2)$ & $8(6.6)$ & $24(8.6)$ \\
\hline Other & $8(5.1)$ & $7(5.8)$ & $15(5.4)$ \\
\hline $\begin{array}{l}\text { Probably or definitely } \\
\text { leaving: }\end{array}$ & $(n=22)$ & $(n=20)$ & $(n=42)$ \\
\hline Working conditions & $16(72.7)$ & $12(60.0)$ & $28(66.7)$ \\
\hline Lifestyle choices & $8(36.4)$ & $6(30.0)$ & $14(33.3)$ \\
\hline Other & $1(4.5)$ & $3(15.0)$ & $4(9.5)$ \\
\hline
\end{tabular}

${ }^{*}$ Some respondents gave more than one comment, so percentages may add up to more than 100.

analysis comprised comments from 1326 of these doctors (the rest did not provide comments or provided comments that we were unable to code), of whom 1047 indicated that they were considering leaving the United Kingdom and 279 were considering leaving medicine. Overall, 16.0\% (212/1326) reported that they were probably not or definitely not going to continue to practise in the United Kingdom, practise medicine, or both. Table 1 summarises the main reasons given for considering leaving the United Kingdom, medicine, or both. Table 2 and table 3 provide a more detailed breakdown of the most common reasons. The box contains exemplar text extracts of reasons given by doctors for leaving medicine, the United Kingdom, or both.

Our response rate of $64.6 \%$, although high for a postal questionnaire survey, might lead to concerns about non-responder bias. As this was the first occasion on which we had surveyed these doctors, our only information about non-responders was their sex and (clinical) medical school attended. In line with our previous surveys, ${ }^{7}$ and the general experience of survey researchers, we had a higher response from women than from men-71.4\% (1568/2195) of women in the cohort and 57.8\% $(1171 / 2026)$ of men responded $\left(\chi^{2}=85.4, \mathrm{df}=1, \mathrm{P}<0.001\right)$. The response rate showed some variation by medical school in $\left(\chi^{2}=80.2, \mathrm{df}=22, \mathrm{P}<0.001\right)$; the only significant outliers (based on analysis of adjusted residuals), both significantly high, were Oxford medical school with $81 \%$ response and Birmingham with $79 \%$ response.

Doctors who were considering leaving the United Kingdom but staying in medicine

Almost two thirds of doctors considering leaving the United Kingdom gave reasons related to lifestyle choices, two fifths gave 
Table 2 Examples of reasons for considering leaving the United Kingdom. Values are numbers (percentages*) of all respondents who did not definitely intend to practise in the United Kingdom for the foreseeable future

\begin{tabular}{|c|c|c|c|c|c|}
\hline Main theme & Description & Women $(n=587)$ & Men $(n=460)$ & Total $(\mathrm{n}=1047)$ & $P$ value \\
\hline \multicolumn{6}{|l|}{ UK working conditions } \\
\hline \multicolumn{2}{|c|}{ All aspects of working conditions, general and specific } & $214(37)$ & $219(48)$ & $433(41)$ & $<0.001$ \\
\hline General & $\begin{array}{l}\text { Poor working conditions in general; poor } \\
\text { state of the NHS; poor working } \\
\text { environment }\end{array}$ & $123(21)$ & $133(29)$ & $256(25)$ & $<0.01$ \\
\hline Pay & $\begin{array}{l}\text { Better pay, higher levels of remuneration } \\
\text { abroad }\end{array}$ & $80(14)$ & $79(17)$ & $159(15)$ & NS \\
\hline Working hours & $\begin{array}{l}\text { Better (shorter) working hours abroad; } \\
\text { "antisocial" hours }\end{array}$ & $61(10)$ & $43(9)$ & $104(10)$ & NS \\
\hline Job satisfaction & $\begin{array}{l}\text { Lack of respect, appreciation, recognition; } \\
\text { undervalued; demoralised, dissatisfied, } \\
\text { poor status, low morale }\end{array}$ & $16(3)$ & $25(5)$ & $41(4)$ & $<0.05$ \\
\hline Career prospects & $\begin{array}{l}\text { Better job opportunities and career } \\
\text { progression abroad }\end{array}$ & $20(3)$ & $21(5)$ & $41(4)$ & NS \\
\hline Financial & $\begin{array}{l}\text { Generally non-specific; better security and } \\
\text { fairer taxation abroad }\end{array}$ & $10(2)$ & $5(1)$ & $15(1)$ & NS \\
\hline Underfunding and facilities & $\begin{array}{l}\text { Better funding of resources for equipment } \\
\text { and facilities abroad }\end{array}$ & $2(<1)$ & $13(3)$ & $15(1)$ & $<0.001$ \\
\hline Training & $\begin{array}{l}\text { Poor quality of training and teaching; } \\
\text { more structured and wider breadth of } \\
\text { training abroad }\end{array}$ & $4(1)$ & $8(2)$ & $12(1)$ & NS \\
\hline Research opportunities & Better research opportunities abroad & $5(1)$ & $7(2)$ & $12(1)$ & NS \\
\hline Stress and pressure & $\begin{array}{l}\text { Less stress and pressure working abroad; } \\
\text { lower public expectations }\end{array}$ & $5(1)$ & $5(1)$ & $10(1)$ & NS \\
\hline Work intensity and workload & Overworked with increasing work intensity & $2(<1)$ & $6(1)$ & $8(1)$ & NS \\
\hline Other & $\begin{array}{l}\text { Lack of specific training or specialty } \\
\text { needs; poor work patterns; discrimination; } \\
\text { litigation }\end{array}$ & $10(2)$ & $13(3)$ & $23(2)$ & NS \\
\hline \multicolumn{6}{|l|}{ Lifestyle choices } \\
\hline All responses relating to lifestyle choices & & $412(70)$ & $270(58)$ & $682(65)$ & $<0.001$ \\
\hline Better quality of life & $\begin{array}{l}\text { Better lifestyle; better quality of life; better } \\
\text { standard of living; outdoor life }\end{array}$ & $73(12)$ & $65(14)$ & $138(13)$ & NS \\
\hline Broaden personal horizons & $\begin{array}{l}\text { Experiencing other countries and cultures; } \\
\text { broadening experience of life; change of } \\
\text { scene, adventure }\end{array}$ & $83(14)$ & $52(11)$ & $135(13)$ & NS \\
\hline Overseas relief/voluntary work & $\begin{array}{l}\text { "Third world" or "developing countries," } \\
\text { medical relief or voluntary work (VSO, } \\
\text { MSF, Red Cross); missionary work }\end{array}$ & $82(14)$ & $40(9)$ & $122(12)$ & $<0.01$ \\
\hline Travel & $\begin{array}{l}\text { Opportunity provided by medicine to work } \\
\text { and travel abroad; travel for its own sake }\end{array}$ & 79 (14) & $39(9)$ & $118(11)$ & $<0.05$ \\
\hline Domestic, family, and personal reasons & $\begin{array}{l}\text { Having family and friends abroad; } \\
\text { following partner to work abroad; } \\
\text { unspecified personal commitments }\end{array}$ & $46(8)$ & $29(6)$ & $75(7)$ & NS \\
\hline Return home to country of origin & $\begin{array}{l}\text { Return to "home country"; return home to } \\
\text { family }\end{array}$ & $46(8)$ & $29(6)$ & $75(7)$ & NS \\
\hline Climate & Better climate and weather abroad & $24(4)$ & $20(4)$ & $44(4)$ & NS \\
\hline Previous experience abroad & $\begin{array}{l}\text { Previous experience of working or living } \\
\text { abroad }\end{array}$ & $18(3)$ & $16(4)$ & $34(3)$ & NS \\
\hline Other & $\begin{array}{l}\text { Long term life or career intention to live } \\
\text { or work abroad; working in the armed } \\
\text { forces }\end{array}$ & $4(1)$ & $11(2)$ & $15(1)$ & $<0.05$ \\
\hline \multicolumn{6}{|l|}{ Work related purpose } \\
\hline To work in medicine abroad for the fores & able future to broaden work experience & $124(21)$ & $60(13)$ & $184(18)$ & $<0.001$ \\
\hline \multicolumn{6}{|l|}{ Other } \\
\hline Visa problems or limitations; intended en & ration & $5(1)$ & 7 (2) & $12(1)$ & NS \\
\hline
\end{tabular}

* Some respondents gave more than one comment, so percentages may add up to more than 100 .

†Differences in response by sex analysed with $\chi^{2}$ test. NS=not significant.

reasons associated with UK working conditions, and almost a fifth of respondents commented on a positive work related purpose in leaving the country (table 1). In the lifestyle responses, the most commonly reported reasons included general comments about seeking a better quality of life, the wish to broaden personal horizons, a wish to do relief work overseas, and the desire to travel (table 2). Under working conditions, the most common comments were about poor working conditions in the United Kingdom, perceived low levels of pay, and excessive working hours. Doctors whose reasons were work related intended to broaden their medical experience by spending some time abroad.
Women were more likely than men to comment that they wanted to work in medicine abroad to broaden their work experience (women $21 \%$, men $13 \% ; \chi^{2}=11.6, \mathrm{P}<0.01$ ), to do relief and voluntary work abroad (women $14 \%$, men $9 \% ; \chi^{2}=7.0$, $\mathrm{P}<0.01$ ), or to travel abroad for its own sake (women $14 \%$, men $9 \% ; \chi^{2}=6.4, \mathrm{P}<0.05$ ). Men were more likely than women to give reasons related to perceived underfunding and poor facilities in the United Kingdom (men 3\%, women $<1 \% ; \chi^{2}=11.3$, $\mathrm{P}<0.001$ ), generally poor working conditions (men $29 \%$, women $21 \% ; \chi^{2}=8.8, \mathrm{P}<0.01$ ), and low levels of job satisfaction (men $5 \%$, women $\left.3 \% ; \chi^{2}=5.0, \mathrm{P}<0.05\right)$. 
Table 3 Examples of reasons for considering leaving medicine. Values are numbers (percentages*) of all respondents who did not definitely intend to practise in the United Kingdom for the foreseeable future

\begin{tabular}{|c|c|c|c|c|c|}
\hline Main theme & Description & Women ( $n=157)$ & Men $(n=121)$ & Total $(n=279) \dagger$ & $P$ value \\
\hline \multicolumn{6}{|l|}{ UK working conditions } \\
\hline \multicolumn{2}{|c|}{ All aspects of working conditions, general and specific } & $114(73)$ & $96(80)$ & $210(75)$ & NS \\
\hline General & $\begin{array}{l}\text { Poor working conditions and working } \\
\text { environment }\end{array}$ & $53(34)$ & $45(37)$ & $98(35)$ & NS \\
\hline Working hours & $\begin{array}{l}\text { Long work hours, which can be } \\
\text { "antisocial" and inappropriately paid }\end{array}$ & $59(38)$ & $29(24)$ & $88(32)$ & $<0.05$ \\
\hline Pay & $\begin{array}{l}\text { Poor, low levels of pay, especially in } \\
\text { relation to hours worked and other } \\
\text { professions }\end{array}$ & $38(24)$ & $30(25)$ & $68(24)$ & NS \\
\hline Job satisfaction & $\begin{array}{l}\text { Dissatisfied, not enjoying medicine, } \\
\text { undervalued, disillusioned, lack of } \\
\text { respect, feeling exploited }\end{array}$ & $29(19)$ & $22(18)$ & $51(18)$ & NS \\
\hline Job/career prospects & $\begin{array}{l}\text { Poor job/career prospects, with lack of } \\
\text { certainty about the future, lack of job } \\
\text { security }\end{array}$ & $6(4)$ & $12(10)$ & $18(7)$ & $<0.05$ \\
\hline Work intensity or workload & $\begin{array}{l}\text { Overworked with pressure of increased } \\
\text { and excessive workloads }\end{array}$ & $7(5)$ & $8(7)$ & $15(5)$ & NS \\
\hline Stress or pressure & $\begin{array}{l}\text { High levels of stress; unreasonable } \\
\text { demands from government, patients, and } \\
\text { public }\end{array}$ & $8(5)$ & $6(5)$ & $14(5)$ & NS \\
\hline Support & $\begin{array}{l}\text { Poor support within work generally, } \\
\text { more specifically from nursing staff and } \\
\text { general public }\end{array}$ & $5(3)$ & $5(4)$ & $10(4)$ & NS \\
\hline Funding or facilities & $\begin{array}{l}\text { Low levels of service funding and poor } \\
\text { facilities }\end{array}$ & 1 (1) & $6(5)$ & $7(3)$ & $<0.05$ \\
\hline Financial & Lack of financial security and prospects & $3(2)$ & $3(3)$ & $6(2)$ & NS \\
\hline Flexible or part time working & $\begin{array}{l}\text { Lack of part time, flexible training and } \\
\text { working }\end{array}$ & $4(3)$ & 1 (1) & $5(2)$ & NS \\
\hline Other & $\begin{array}{l}\text { Comments about bureaucracy, litigation, } \\
\text { media bashing }\end{array}$ & $6(4)$ & $10(8)$ & $16(6)$ & NS \\
\hline \multicolumn{6}{|l|}{ Lifestyle choices } \\
\hline \multicolumn{2}{|c|}{ All responses relating to lifestyle choices } & $47(30)$ & $16(13)$ & $63(23)$ & $<0.001$ \\
\hline Quality of life & Poor lifestyle and quality of life & $12(8)$ & $11(9)$ & $23(8)$ & NS \\
\hline Domestic or social reasons & $\begin{array}{l}\text { Family commitments; following partner's } \\
\text { work abroad }\end{array}$ & $15(10)$ & $2(2)$ & $17(6)$ & $<0.01$ \\
\hline Broaden life experience & $\begin{array}{l}\text { Not work related; diversity of experience } \\
\text { including experiencing different cultures }\end{array}$ & $8(5)$ & $3(3)$ & $11(4)$ & NS \\
\hline Travel & $\begin{array}{l}\text { Desire to travel and travel for its own } \\
\text { sake }\end{array}$ & $8(5)$ & $2(2)$ & $10(4)$ & NS \\
\hline Climate & Better climate and weather abroad & $1(1)$ & 0 & $1(<1)$ & NS \\
\hline \multicolumn{6}{|l|}{ Work related purpose } \\
\hline Considering or have other car & or interests & $16(10)$ & $8(7)$ & $24(9)$ & NS \\
\hline \multicolumn{6}{|l|}{ Other } \\
\hline All other responses & & $8(5)$ & $7(6)$ & $15(5)$ & NS \\
\hline
\end{tabular}

Respondents who reported that they were probably or definitely going to leave the United Kingdom mentioned lifestyle choices much more often than working conditions (table 1). In the detailed breakdown (not shown in the tables), responses were spread over several factors: the desire to undertake overseas relief work (mentioned by 32 doctors); return to country of family origin (30 doctors); domestic, family, and personal reasons (20 doctors); travel (19 doctors); broadening personal horizons (18 doctors); and quality of life factors (17 doctors). Of these respondents, $22.6 \%(237 / 1047)$ gave reasons related to working conditions alone, and 43.3\% (453/1047) gave reasons related to lifestyle choices alone.

\section{Doctors who were considering leaving medicine}

Three quarters of doctors considering leaving medicine gave reasons related to UK working conditions, about one fifth gave reasons associated with lifestyle choices, and about one twelfth gave a positive work related purpose for wanting a different career (table 1). The most commonly reported comments about UK working conditions concerned long and unsocial working hours, low levels of pay, and dissatisfaction with working in medicine (table 2). Under the heading of lifestyle choices, the most common comments were about quality of life factors; domestic, family, and personal reasons; and the desire to broaden life experiences and travel. Those whose reasons were work related reported that they were considering, or had available to them, other career interests and options.

Women were more likely than men to refer to general lifestyle choices (women 30\%, men 13\%; $\chi^{2}=10.9, \mathrm{P}<0.001$ ), domestic and social commitments (women 10\%, men $2 \%$; $\left.\chi^{2}=7.4, \mathrm{P}<0.01\right)$, and onerous working hours that could be "antisocial" (women 38\%, men 24\%; $\chi^{2}=5.8, \mathrm{P}<0.05$ ). Men were more likely than women to mention poor job and career prospects (men 10\%, women $4 \% ; \chi^{2}=4.2, \mathrm{P}<0.05$ ) and perceived low levels of funding and poor facilities in UK medicine (men $5 \%$, women $1 \% ; \chi^{2}=5.2, \mathrm{P}<0.05$ ).

Respondents who reported that they were probably or definitely going to leave medicine also cited UK working conditions much more often than lifestyle choices (table 1). In the 


\section{Quotations from the doctors who were considering leaving UK medicine}

(Grouped into reasons given; each quote is from a different doctor and is reproduced as originally written)

\section{Working conditions}

Working conditions as a motivation to go abroad

Better working hours in other countries

... hope for better working conditions, especially hours

Desire to go abroad where hours are shorter

Working in a country where you are paid for hours worked and at reasonable rates

Poor working conditions and pay in UK medicine. Love the job, hate the fact I feel abused doing it

Working conditions as a motivation to leave medicine

Terrible working conditions and hours for UK doctors

The long hours and impossible working conditions experienced in my medical house job

Leaving medicine because of poor rate of pay in relation to

hours worked and sacrifices involved

Unable to perform to a satisfactory level (for myself) due to workload and hours, i.e. poor job satisfaction.

A dreadful, dangerous, unsupported system that ruthlessly exploits juniors and views them as more expendable than venflons.

\section{Working conditions with lifestyle or social factors}

Working conditions with lifestyle or social factors as a motivation to go abroad

More sociable hours in e.g. Australia.

Experience of living abroad, travelling, better pay, better hours

and more time to enjoy life out of work

Hope of better hours and better family life

Working conditions with lifestyle or social factors as a motivation to leave medicine

I want a life which allows other interests and spare time

Unsociable hours, having no life outside of medicine a lot of the time

Hours and fatigue dominating private and personal life too much

\section{Lifestyle choices}

Lifestyle choices as a motivation to go abroad

Preferable social conditions overseas

Better lifestyle options abroad, especially for doctors

I would like to work abroad for a time, in order to experience different culture/lifestyles

Experiencing the cultures and people of other countries generally, not only different medicine

Would like to live in other part of the world, where there is arguably a greater need for doctors e.g. Africa/L.America Wish to work involving third world and humanitarian issues I would like to do aid work, e.g. Medicins Sans Frontieres for a few years

Always intended to take advantage of the opportunity to travel/work abroad which medicine offers

I enjoy travelling

\section{Lifestyle choices as a motivation to leave medicine}

I do not enjoy the lifestyle that surgery provides and I am not interested enough in other areas to pursue a career Other careers promote better lifestyle

Personal. Husband moving overseas. Unenthusiastic to stay in UK NHS system

Family reasons and future relationships

Broaden my horizons. Live to the full and be satisfied and happy

I don't know what the future holds but I want to travel

Two reasons-want to travel and find I would sooner give up

medicine than work in the NHS as I have found it so far detailed breakdown (not shown in the tables), lack of job satisfaction (mentioned by 14 doctors) was the most important factor for the subgroup who were probably or definitely intending to leave medicine, ahead of general comments on working conditions (nine doctors), working hours (nine doctors), or pay (eight doctors). Of these respondents, 59.1\% (165/279) gave reasons relating to working conditions alone, and 9.0\% $(25 / 279)$ gave reasons related to lifestyle choices alone.

\section{Respondents who definitely intended to pursue a career in}

\section{UK medicine}

This study focused on the views of those doctors who did not definitely wish to pursue a career in UK medicine. We did not ask the doctors who were definite about a UK career to give their reasons. However, all respondents were asked to respond to several attitude statements, and we compared the responses of doctors who were definite about a UK career with the responses of those who were not. We thought a priori that these two groups may differ in their views of their career prospects, their career advice, their enjoyment of the pre-registration house officer year and the leisure time they had available, and the confidence they had in their current career choice, so we examined the results from attitude statements related to these topics.

Presented with the statement "I am satisfied with my future career prospects," $73.3 \%(602 / 821)$ of those doctors who definitely intended a UK career agreed or strongly agreed, compared with $59.9 \%(925 / 1543)$ of those who were not definite about a UK career $\left(\chi^{2}=41.3, \mathrm{df}=1, \mathrm{P}<0.001\right)$. We found no significant difference between the two groups on the statement "I have been able to obtain useful career advice since graduation," for which the corresponding percentages were $39.5 \%(323 / 817)$ and $35.8 \%(558 / 1557)\left(\chi^{2}=3.0, \mathrm{df}=1, \mathrm{P}=0.08\right)$. Those who were definite about a UK career had a mean score of 7.3 when asked to score the statement "How much have you enjoyed the PRHO year overall?" on a scale from 1 (not enjoyed it at all) to 10 (enjoyed it greatly), compared with a mean score of 6.8 for those not definite $(t$ test, $\mathrm{P}<0.001)$. Those who were definite about a UK career had a mean score of 4.8 when asked to score the statement "How satisfied are you with the amount of time the PRHO year has left you for family, social, and recreational activities?" on a scale from 1 (not at all satisfied) to 10 (extremely satisfied), compared with a mean score of 4.3 for those not definite ( $t$ test, $\mathrm{P}<0.001)$. When asked "Have you made up your mind about your choice of long term career?" and asked to reply definitely, probably, or not really, those certain about a UK career were more likely to reply "definitely"-35.8\% (332/927) compared with $21.6 \%(380 / 1756)$ of those not definite about a UK career $\left(\chi^{2}=61.8, \mathrm{df}=1, \mathrm{P}<0.001\right)$.

\section{Discussion}

The number of doctors who were considering leaving the United Kingdom, but staying in medicine, was considerably greater than the number considering leaving medicine. This accords with our evidence on what doctors actually do if they leave UK medicine: many more work abroad, but stay in medicine, than leave medicine. $^{489}$ For those doctors who were considering leaving the United Kingdom, lifestyle choices were important to a larger number of doctors than were working conditions, although working conditions were cited as important by about $40 \%$. In contrast, those doctors considering leaving medicine were much more likely to cite working conditions as a reason and were less concerned about lifestyle choices. Overall, nearly one third of the respondents who were considering leaving the United Kingdom, medicine, or both gave reasons solely related to working 
conditions. This suggests that these doctors might be persuaded to commit themselves to working in UK medicine if working conditions in the NHS improved. The analysis of the detailed breakdown of reasons given by doctors indicates that policy initiatives would be most effective if targeted at pay and at long and unsocial working hours.

Men and women gave broadly similar reasons for intending to work in medicine abroad. Women were a little more likely than men to refer to lifestyle choices associated with doing overseas relief or voluntary work, the desire to work abroad to broaden their experience, or a wish to travel for its own sake. Women who were considering leaving medicine were motivated to do so by their lifestyle choices, especially those related to domestic and social factors. Men tended to give reasons that were largely associated with direct, day to day work activities: poor working conditions, underfunding and poor facilities, low levels of job satisfaction, and poor job and career prospects. This was the case whether male respondents were considering leaving the United Kingdom or leaving medicine. This suggests that young women doctors continue to find it difficult to balance the demands of work and their domestic and social responsibilities and needs, whereas young male doctors largely focus on factors that are directly related to work and career.

The study's main focus was on reasons that led some young doctors to feel disaffection with UK medicine. However, we can also say a little about the motivating factors for those who said they definitely intended a UK medical career. They showed greater satisfaction with their career prospects, had enjoyed the pre-registration house officer year more, and had been more satisfied with the leisure time available to them than had their colleagues who wished to leave. They were also considerably more definite about their long term career choices. Interpreting these results is difficult, but they hint that those doctors who definitely intend to remain in UK medicine may have a more realistic attitude to the practicality of a medical career than others.

Working hours have been subject to recent government policy initiatives. The reduction of working hours, and changes in working patterns to accommodate this reduction, have been progressing as a result of the "new deal" and the European Working Time Directive. ${ }^{10}{ }^{11}$ Compliance with targets on reduced working hours has improved nationally: from $61.6 \%$ in 2000 to $79.0 \%$ in $2003 .^{12}{ }^{13}$ This suggests that very long and unsocial working hours should soon no longer be a fundamental feature of UK postgraduate medical training. However, problems remain in fully complying with working hours regulations within the timeframe required. In addition, the reforms to training at senior house officer level, and the need to ensure that there are enough doctors at all grades to provide 24 hour cover, ${ }^{14}$ probably means that problems related to working hours and their unsocial effect will continue for some time. Concern also exists about whether the reduction in working hours will reduce doctors' opportunities to gain enough experience to become adequately trained. ${ }^{14}$ Current policy documents make it clear that the Department of Health and the NHS are attempting to tackle adverse working conditions. ${ }^{23}{ }^{11}$ If the benefits of the recent large increase in the numbers of UK medical students are to be fully realised in the NHS, measures must be taken to minimise avoidable attrition.

We thank all the doctors who participated in the survey. We also thank Karen Hollick for administering the surveys and Janet Justice and Alison Stockford for data preparation.

Contributors: All authors planned the study. PJM and TWL analysed the data. PJM, TWL, and MJG wrote the first draft. All authors contributed to subsequent drafts and approved the final version. All are guarantors.

\section{What is already known on this topic}

The loss of UK trained junior doctors to work overseas has been a longstanding concern of policy makers

The reasons why some UK trained doctors wish to leave the United Kingdom or the NHS, or to leave medicine altogether, have not been explored systematically among recent graduates

\section{What this study adds}

Of the junior doctors who may leave UK medicine (almost half of those studied), the wish to work in medicine abroad is much more common than the wish to leave the profession

Two thirds of doctors wanting to work in medicine abroad gave personal lifestyle reasons, whereas those wanting to leave medicine altogether mainly gave reasons related to UK working conditions

Changes of policy to tackle adverse working conditions and to improve working lives are important in minimising avoidable attrition from the UK medical workforce

Funding: The UK Medical Careers Research Group and the Unit of Health Care Epidemiology are funded by the Department of Health.

Competing interests: None declared.

Ethical approval: The design and content of the surveys has been overseen by an external advisory group, convened by the Department of Health, including representation from postgraduate medical deans and the British Medical Association.

1 Department of Health. The NHS plan: a plan for investment, a plan for reform. London: Department of Health, 2000

2 Department of Health. Investment and reform for NHS staff-taking forward the NHS plan. Department of Health. London, 2001.

3 Department of Health. Delivering the NHS plan: next steps on investment, next steps on reform. Norwich: Stationery Office, 2002.

Goldacre MJ, Lambert TW, Davidson JM. Loss of British-trained doctors from the medical workforce in Great Britain. Med Educ 2001:35:337-44.

5 Lambert TW, Goldacre MJ, Parkhouse J. Intentions of newly qualified doctors to practise in the United Kingdom. BMJ 1997;314:1591-2.

6 Parkhouse J. Doctors' careers: aims and experiences of medical graduates. London: Routledge, 1991.

7 Lambert TW, Goldacre MJ, Edwards C, Parkhouse J. Career preferences of doctors who qualified in the United Kingdom in 1993 compared with those of doctors qualifying in 1974, 1977, 1980, and 1983. BMJ 1996;313:19-24

8 Lambert TW, Goldacre MJ. Career destinations seven years on among doctors who qualified in the United Kingdom in 1988: postal questionnaire survey. BMJ 1998:317:1429-31.

9 Davidson JM, Lambert TW, Goldacre MJ. Career pathways and destinations 18 years on among doctors who qualified in the United Kingdom in 1977: postal questionnaire survey. BMJ 1998;317:1425-8.

10 NHS Management Executive. Junior doctors: the new deal. London: Department of Health, 1991.

11 Department of Health. Guidance on working patterns for junior doctors, Nov 2002 www.dh.gov.uk/assetRoot/04/06/63/66/04066366.pdf (accessed 28 Sep 2004).

12 Department of Health. Junior doctors' contract compliance rates: summary 2000. www.dh.gov.uk/assetRoot/04/03/46/16/04034616.pdf (accessed 28 Sep 2004).

13 Department of Health. Junior doctors' contract compliance rates: summary 2003. www.dh.gov.uk/assetRoot/04/03/45/17/04034517.pdf (accessed 28 Sep 2004).

14 Royal College of Physicians. The further implementation of the European Working Time Directive to cover junior doctors in training. London: Royal College of Physicians, 2003.

(Accepted 6 September 2004)

doi 10.1136/bmj.38247.594769.AE

UK Medical Careers Research Group, Unit of Health-Care Epidemiology, Department of Public Health, University of Oxford, Oxford OX3 7LF Philip J Moss social scientist

Trevor W Lambert study coordinator

Michael J Goldacre professor of public health

Penelope Lee research officer

Correspondence to: M J Goldacre michael.goldacre@dphpc.ox.ac.uk 